\title{
Tumors Derived from Langerhans Cells
}

National Cancer Institute

\section{Source}

National Cancer Institute. Tumors Derived from Langerhans Cells. NCI Thesaurus. Code C150692.

This category includes two main sub-groups, according to the degree of cytological atypia and clinical aggressiveness: Langerhans cell histiocytosis and Langerhans cell sarcoma. (WHO 2017) 